\title{
Putting the Pieces Back Together Again: Contest Webs for Large-Scale Problem Solving
}

\author{
Thomas W. Malone ${ }^{1}$, Jeffrey V. Nickerson ${ }^{2}$, Robert J. Laubacher ${ }^{1}$, Laur Hesse Fisher ${ }^{1}$, \\ Patrick de Boer ${ }^{1,3}$, Yue Han ${ }^{2}$, and W. Ben Towne ${ }^{4}$ \\ ${ }^{1}$ MIT Center for Collective Intelligence, Cambridge, MA, USA, \{malone, rj1, 1fi, pdeboer\}@mit.edu \\ ${ }^{2}$ Stevens Institute of Technology, Hoboken, NJ, USA, \{jnickerson, yhan4\}@stevens.edu \\ ${ }^{3}$ University of Zurich, Zurich, Switzerland \\ ${ }^{4}$ Carnegie Mellon University, Pittsburgh, PA, USA, wbt@cs.cmu.edu
}

\begin{abstract}
A key issue, whenever people work together to solve a complex problem, is how to divide the problem into parts done by different people and combine the parts into a solution for the whole problem. This paper presents a novel way of doing this with groups of contests called contest webs. Based on the analogy of supply chains for physical products, the method provides incentives for people to (a) reuse work done by themselves and others, (b) simultaneously explore multiple ways of combining interchangeable parts, and (c) work on parts of the problem where they can contribute the most.
\end{abstract}

The paper also describes a field test of this method in an online community of over 50,000 people who are developing proposals for what to do about global climate change. The early results suggest that the method can, indeed, work at scale as intended.

\section{Author Keywords}

Collective intelligence; climate change; contests; contest webs; knowledge reuse; coordination; incentives

\section{ACM Classification Keywords}

Categories and subject descriptors: H.5.3 [Information interfaces and presentation]: Group and organizational Interfaces: Collaborative computing, Computer-supported cooperative work, Organizational design, Theory \& models.

\section{INTRODUCTION}

Whenever people work together to solve any kind of problem, the problem must somehow-even if unconsciously-be divided into pieces done by different people. And once the problem has been divided, the solutions to the different pieces must somehow be

Permission to make digital or hard copies of part or all of this work for personal or classroom use is granted without fee provided that copies are not made or distributed for profit or commercial advantage and that copies bear this notice and the full citation on the first page. Copyrights for third-party components of this work must be honored. For all other uses, contact the Owner/Author.

Copyright is held by the owner/author(s)

$C S C W^{\prime} 17$, February 25 - March 01, 2017, Portland, OR, USA

ACM 978-1-4503-4335-0/17/03.

http://dx.doi.org/10.1145/2998181.2998343 combined into a solution for the overall problem. These two coordination processes-dividing and combining-are done in many different ways in many different situations ranging from small workgroups to huge hierarchies to global markets. The CSCW community has long been interested in these processes, and especially of late in ways of creating complex artifacts from simpler components (e.g. $[14,23-25,28,38])$.

We propose here a novel approach for using online contests to carry out these two processes. Based on the analogy of supply webs for physical products, we call this approach contest webs. Unlike traditional online contests, a contest web includes a family of related contests, some of which explicitly involve combining ideas from others. And unlike other organizational alternatives such as the hierarchies common in businesses and the consensus decision-making of Wikipedia, this approach encourages simultaneous exploration of many alternative combinations of pieces created by different people.

The principal contribution of the paper is to articulate this new approach and to describe the system and the online community we developed to implement it. The online community, called Climate CoLab, includes over 50,000 people who are addressing the complex problem of what to do about global climate change.

We focus, in this paper, on the system design and the rationale for that design, leaving detailed evaluation for future papers. We do include here, however, some empirical results from pilot testing the system in the Climate CoLab community. This pilot testing helped answer questions about whether the approach could work at all in a large, diverse community. We focused, in particular, on two key questions: Would people actually reuse their own and others' work as we intended? And would they simultaneously explore multiple combinations of interchangeable parts? After answering these questions, the paper reflects on when this approach may be useful and how the system we developed might be used for many other types of problems in different situations. 


\section{BACKGROUND AND RELATED WORK}

\section{Coordinating large-scale problem-solving}

Theorists in many different fields have discussed ways of dividing and combining parts of complex processes. For example, Adam Smith [41] described the potential productivity benefits of dividing a single task done by one person (such as making pins) into many smaller tasks done by different people (such as cutting the wires and sharpening the points). Simon [40] talked about the virtues of decomposing a complex system into hierarchically nested, mostly independent, modules. Lawrence and Lorsch [29] discussed the importance, in large organizations, of differentiation and integration, that is, dividing the organization into specialized subunits and then integrating these units to achieve the goals of the overall organization. And a number of theorists have analyzed different kinds of coordination processes for decomposing tasks and for managing the interdependencies needed to integrate the subtasks $[30,31,43,47]$.

Two of the most common approaches for dividing and combining subparts of complex human processes involve hierarchies and markets. Most of us have daily experience of how managers in hierarchical organizations delegate subtasks to different people and then coordinate the combined efforts of these different people. And a voluminous literature on organizational design analyzes different ways of doing these things (e.g. [17,29,34]).

Markets also provide a way of coordinating the same kinds of activities that can be coordinated by hierarchies $[12,47]$. For instance, when General Motors (GM) needs tires to put on its cars, one option it has is to manufacture the tires itself. In this case, GM would use its own internal hierarchy to coordinate aspects of the tire-making process such as the characteristics and delivery times of the tires. But GM also has the option of buying the tires from an outside company, like Goodyear. In this case, GM would outsource the tiremaking activities to Goodyear and coordinate these activities by negotiating with Goodyear about things like product characteristics, delivery times, and price.

Of course, individual markets don't exist in isolation; they are usually part of broader supply chains that assemble many levels of components, subcomponents, and raw materials into finished products. For instance, GM may buy car seats from Johnson Controls and audio systems from Mitsubishi. And Mitsubishi may, in turn, buy integrated circuits from Intel and plastic from DuPont. In fact, the complex pattern of all these different tiers of suppliers is usually more accurately described as a "supply web" than as a simple, linear "supply chain" [10].

At each level of a supply web, different suppliers compete with other suppliers at the same level, but they cooperate with the buyers of their products and with the suppliers of their own subcomponents and raw materials. And at each level, the suppliers of integrated products are responsible for making sure that the combination of subcomponents they assemble are compatible with each other and collectively sufficient to meet the customers' needs.

The presence of markets for all these subcomponents helps them find the pieces they need. And-importantly-the fact that competitors at each level can simultaneously explore multiple combinations of subcomponents increases the chances that the system as a whole will find innovative new solutions and adapt to changing situations [6,46,51].

CSCW tools for coordinating collective problem-solving A number of recent efforts in the CSCW community have focused on how to combine individual contributions to achieve larger goals. For instance, several projects have emphasized developing automated tools to help manage global constraints that are specific to situations such as travel itinerary planning [50], conference scheduling [8,22], and taxonomy development [9]. Unlike these systems, the work we describe here relies primarily on humans to manage global constraints. Thus our approach is widely applicable, even in situations where there are no obvious ways of automating the management of these constraints.

Another group of projects has focused on letting humans subdivide a large problem into subparts in a top-down, hierarchical manner [25,38]. Like our work, these systems are widely applicable, because they let humans combine subparts into solutions for the overall problems without relying on automated constraint management. But these systems focus on exploring only one solution at a time, and they provide only limited support for reusing results from previous work. Unlike these systems, our work encourages groups to make extensive reuse of previous work done by others and to simultaneously explore many different ways of combining partial solutions into solutions for the overall problem.

Online contests as a tool for collective problem-solving There has also been a great deal of interest recently in using online contests as a tool for collective problem solving. For example, different organizations have used various forms of contests for spurring innovation (e.g. InnoCentive, [2,13], OpenIDEO [27]), for developing software (e.g. TopCoder, [26]) and for writing encyclopedia articles (e.g. CrowdForge [24]). Some previous research has focused on reusing ideas from contests like these to stimulate other ideas $[7,48,49]$, but with few exceptions (e.g. [35]), this work has not focused-like ours does-on combining multiple previous ideas to create more complex solutions.

Even though most people wouldn't think of it this way, we can view a contest as a special kind of market. The contest sponsor is the "buyer," and the contestants are the potential "sellers." Just as sellers compete in a market to sell their products to buyers, contestants compete in a contest to have their entries selected by judges acting on behalf of the buyer. The contest sponsor usually posts "prices" in advance (e.g., awards that the winning contestants will 
receive), and the winning contestants usually "sell" to the contest sponsor some rights to use their contest entries.

However, a single contest doesn't provide any particular support for creating complex products. If a group of people works together to create a complex entry, for instance, the contest structure itself doesn't help them coordinate their work. Instead, they need to recruit team members on their own and organize among themselves the combining of different pieces done by different team members.

As we've seen above, however, the network of different markets in a supply web helps coordinate precisely these kinds of interactions for creating the various subcomponents of complex products. A key insight of this paper is that just as markets in a supply web can combine the results of other markets, so, too, contests in a contest web can combine the results of other contests.

The hypothesis we explore in this paper, therefore, is that contest webs can help groups of people solve complex problems in many domains by simultaneously exploring many possible combinations of reusable subparts developed by themselves and others.

\section{WHAT IS A CONTEST WEB?}

We first define a contest family as a collection of different contests that, together, systematically cover different aspects of a complex problem. Thus, a contest family is analogous to a collection of different markets for related products, such as all the markets for different kinds of auto parts.

We next define an integrated contest as a contest in which the entries explicitly combine entries from other contests in the same contest family. Thus an integrated contest is analogous to a market for complex products (like automobiles), which include parts (like tires and seats).

Finally, we define a contest web as a contest family that includes one or more integrated contests. Thus, a contest web is analogous to all the markets in the automotive industry, including both those for auto parts and for finished autos. In the following sections, we describe how we made the design choices needed to create a contest web called Climate CoLab.

\section{CLIMATE COLAB}

The MIT Climate CoLab platform allows people from all over the world to develop proposals for what we should do about climate change (Figure 1) [20,21,32,33]. The proposals can include any ideas users have for technical, economic, political, or other changes that should be made, as well as discussions of how the changes could be made, why they are feasible, and why they are desirable.

The primary way of organizing activity in the CoLab has been through a collection of online contests. In the first three years that the Climate CoLab site was publicly available (2009-2011), we created one or two contests per year with general topics like "What international climate agreements should the world community make?"

Then, in 2013, we introduced the notion of contest families, and in each of the following years, we have had 17 or more contests per year on topics ranging from how to generate electricity with fewer emissions to how to adapt to sea level rise caused by climate change.

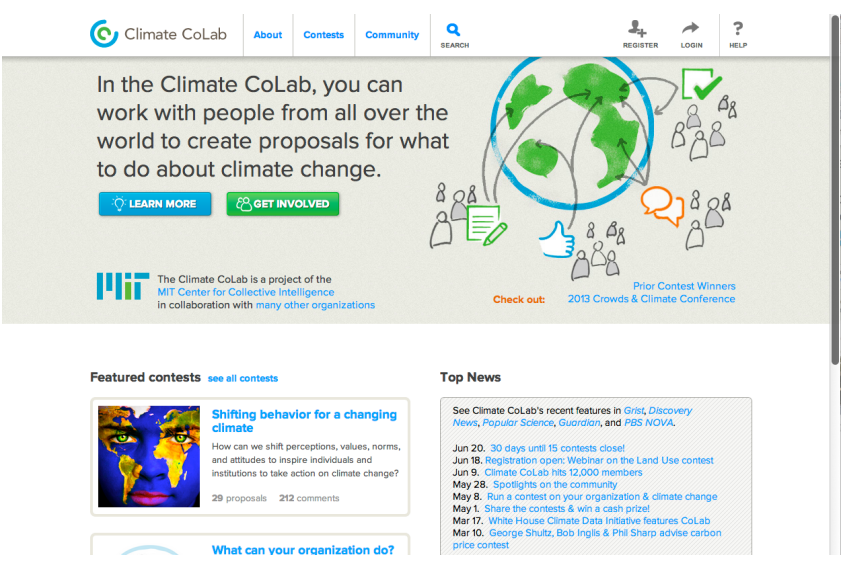

Figure 1. Climate CoLab home page. Key parts of the system are accessible via the tabs at the top of the page for About, Contests, and Community.

In each contest, after members submit proposals, expert judges we recruit first select semifinalists and give suggestions for improvements. After the semifinalists revise their proposals, judges select the most promising entries to be finalists. Then from the finalists, the judges select the Judges' Choice Award winners and the community votes for the Popular Choice Award winners.

The winners of these awards each year are also eligible for one overall Grand Prize (which in the past three years has been $\$ 10,000$ ), and they have an opportunity to present their work to potential implementers and others in the annual Climate CoLab conferences.

In 2015, we introduced integrated contests, thus making Climate CoLab a contest web. As part of this change, we added another prize purse (currently \$10,000) for contributions to integrated proposals (as described below). All prize money so far has come from our research funds.

By the conclusion of the studies described here, more than 400,000 people from virtually every country in the world had visited the Climate CoLab website, over 50,000 had registered as members of the community, and they had submitted nearly 1,500 proposals.

The current operational system is publicly available at http://climatecolab.org, and its open-source software is at https://github.com/CCI-MIT/XCoLab.

\section{Climate CoLab proposals}

To create a proposal, authors fill in a template with fields such as a summary of the overall idea, descriptions of who would implement the idea, estimated costs, and expected 
benefits (see Figure 2). Each proposal also includes tabs for information such as estimated impacts on carbon emissions, authors of the proposal, and comments from community members. Some proposals (like the one in Figure 2) include videos or other graphical illustrations

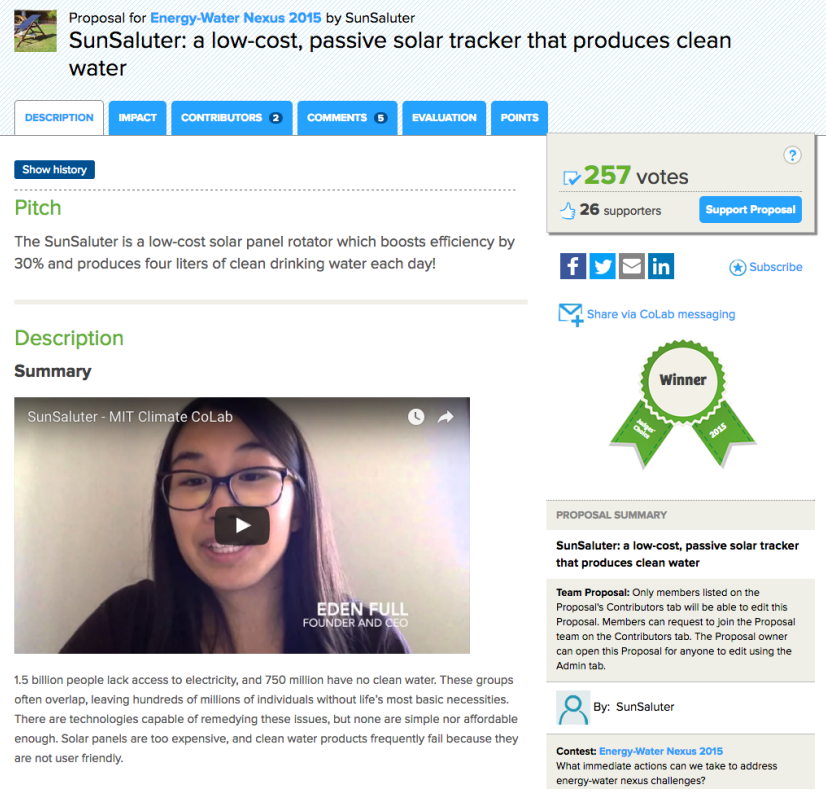

Figure 2. Sample Climate CoLab proposal (Image courtesy of Eden Full)

The sample proposal shown in Figure 2 won the Grand Prize in 2015. It describes a device called SunSaluter, a rotating solar panel that uses dripping water and gravity to follow the sun across the sky while also filtering the water into clean drinking water.

Other winning proposals have included (a) an approach for using aerial infrared photography superimposed on Google Maps to show people how much wasted heat is escaping from their homes in comparison to their neighbors, (b) an effort in China to develop and popularize an aspirational lifestyle for Chinese consumers, called the "China Dream," that is more environmentally sustainable than the "American Dream," and (c) a way for individual countries to charge emission levies for ocean shipments to and from their ports without violating international law, without providing significant economic incentives for shippers to avoid their ports, and without requiring global agreements.

\section{BREAKING THE PROBLEM INTO PIECES: CONTEST FAMILIES}

\section{A taxonomy of the problem}

To create contest families for the complex problem of what humans should do about climate change, we (as the contest organizers) first created a taxonomy of the different parts of the problem. While there is, in general, no single correct taxonomy for a given problem domain, we tried in our taxonomy to satisfy several desirable criteria: (a) The taxonomy as a whole should cover the space of possible solutions so that any plausible solution component should fit somewhere in the taxonomy.

(b) In each dimension of the taxonomy, the categories should be mutually exclusive and collectively exhaustive. In other words, the categories in a dimension should not overlap each other and should collectively cover all possibilities for that dimension.

(c) The taxonomy should reflect distinctions that experts in the area know are important.

(d) The taxonomy should be simple and intuitive enough for the intended users to understand relatively easily. In our case, the intended users are a broad segment of the general population, not just climate change experts. For a more detailed description of the community membership, see [15].

Bearing these criteria in mind, we studied the literature on climate change (e.g. [42]) and worked with a number of experts in this domain to create a taxonomy for the climate change problem. The taxonomy we created includes four dimensions phrased as questions: What actions will be taken, Where will the actions be taken, Who will take the actions, and How will the actions be taken (see Figure 3). Each of these dimensions can be further broken down to arbitrarily detailed levels, and any action or contest related to climate change can be classified on one or more of these dimensions. For instance, a contest about what physical actions electronics manufacturers in the US could take to reduce emissions from their factories would be classified under items 1.1.4, 2.2.1, 3.2, and 4.1 in Figure 3.

Many other important problems (such as those involving economic inequality, education, and public health) can be characterized with a similar taxonomy. The only dimension in our taxonomy that is specific to the climate change problem is the What dimension. Other problems would have different values for the What dimension, but the Where, Who, and How dimensions are immediately applicable to a wide range of other problems.

\section{Mapping contests to the taxonomy}

Using this taxonomy as a guide, we created a set of contests that covered the space of possibilities on the What dimension. In recent years, we did this using approximately the categories shown in Figure 3, item 1. Of course, we could have done this using a different dimension, but we started with the What dimension since the categories in this dimension were especially important in the literature about climate change.

In addition to these "coverage" contests, we also included a selection of more specialized contests focusing on specific questions that were either (a) particularly important parts of the overall problem or (b) of particular interest to our partner organizations. For instance, many experts on climate change policy say that a critical leverage point in addressing climate change would be to have some kind of price on carbon emissions (e.g., a carbon tax). For this 
reason, we have had specialized contests on this topic in several years.

1. What (actions will be taken)

1.1. Reduce greenhouse gas (GHG) emissions (Mitigation)

1.1.1. Energy supply

1.1.2. Buildings

1.1.3. Transportation

1.1.4. Industry

1.1.5. Land use and other sectors

1.2. Adapt to climate change (Adaptation)

1.3. Reduce the warming effects of GHG emissions (Geoengineering)

2. Where (will the actions be taken)

2.1. Global

2.2. National

2.2.1. US

2.2.2. China

2.2.3....

3. Who (will take the actions)

3.1. Governments

3.2. Businesses

3.3. Other organizations

3.4. Individual citizens and consumers

4. How (will the actions be taken)

4.1. Physical actions

4.2. Political actions

4.3. Economic actions

4.4. Cultural actions

Figure 3. Partial view of the current Climate CoLab taxonomy

To help Climate CoLab users see the relationships among the different contests and categories, the system provides an Outline View that shows which contests (from any year) are included in each category (see Figure 4).

\section{Alternative approaches to defining contest families}

In the Climate CoLab contests we have had so far, we as the contest organizers defined the contests in the contest family. But there are other ways to do this. For instance, one obvious possibility is to let the people who create proposals in integrated contests (called "integrated proposals") also create their own sub-contests. Then, other users could create proposals to fill specific needs that the integrated proposal creators identify themselves. This approach to problem decomposition would be similar to that used by, for example [25], [28], and [38].

A disadvantage of this approach, however, is that it would not encourage interchangeable sub-proposals. Subproposals submitted into contests created by one integrated proposal creator would not, in general, be suitable for inclusion into other integrated proposals. This approach, therefore, fails to take full advantage of the benefits of interchangeable parts that are often very important in realworld supply webs $[6,18]$.

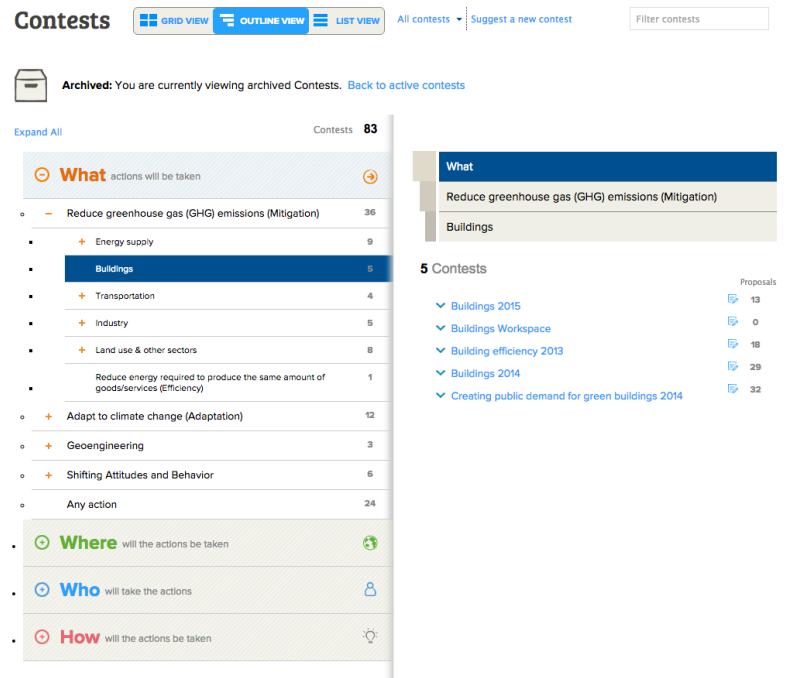

Figure 4. The Outline View shows an expandable version of the contest taxonomy in the left column. The right column shows all current (and/or previous) contests about the topic selected in the left column.

To maximize these benefits, our experiments with Climate CoLab to date have used a set of pre-defined contests defined to provide an "architecture" for solving the problem [6]. This architecture is directly analogous to product architectures that are often very useful in real-world supply webs (such as the "Wintel" PC architecture based on the Windows operating system and Intel microprocessors) [6]. This increases the chances that the creators of different integrated proposals will be able to use various combinations of mostly interchangeable sub-proposals from other contests.

\section{PUTTING THE PIECES BACK TOGETHER: INTEGRATED CONTESTS}

Once a problem has been divided into different contests for different sub-parts of the problem, contest webs use integrated contests to create solutions for larger and larger parts of the whole problem. This means that entries in an integrated contest should combine entries from other contests in ways that are (a) mutually compatible and (b) collectively sufficient.

To be mutually compatible, the different parts of an integrated contest entry should not violate any important constraints. For instance, if all the parts must be paid for from the same budget, then their total cost must not exceed the total budget. Or if some parts require there to be a global carbon tax, and other parts require that there not be a global carbon tax, then the parts are not mutually compatible.

To be collectively sufficient, the combination of all the parts must be enough to solve the problem to a satisfactory degree. For instance, if the goal of a country's climate plan 
is to reduce emissions by $40 \%$, but the combined emission reductions of all the sub-parts currently included will only reduce emissions by $10 \%$, then the entry is not sufficient to solve the problem.

\section{Integrated contests in Climate CoLab}

In the most recent year (2015), we used two levels of integrated contests, defined on the Where dimension:

a) One global contest for climate plans for the whole world, and

b) Six regional contests for climate plans for the four largest emitting countries (US, Europe, China, India) and two other regions that include the rest of the world (Other Developed Countries and Other Developing Countries).

In addition to these integrated contests, we also had 15 basic contests on topics like energy supply, buildings, transportation, carbon price, and shifting attitudes and behavior.

As suggested in Figure 5, proposals in regional contests could include any combination of proposals from the basic contests. Proposals in the global contest were required to include one proposal from each of the regional contests, and they were also allowed to include additional proposals from the basic contests that applied across regions.

The templates for integrated proposals include special fields where authors indicate which other proposals this one includes by adding links to those other proposals. For instance, the template for global proposals includes a field for each region and tools to help users insert one regional proposal from the appropriate region into each field. The templates also include places where authors describe how the different sub-proposals fit together and what their combined emission reductions are likely to be.

As an example, the winner of the Judges' Choice award in the 2015 Climate CoLab global contest was a proposal called "Solar Dollars." This proposal suggested how a digital currency (based on Bitcoin-like blockchain technology) could be used to incentivize emission reductions in countries around the world. The global proposal contained sub-proposals for how each of the major countries and regions of the world could contribute to the overall plan. The sub-proposal for Europe, for instance, described how Greece could be used as a test laboratory for renewable energy approaches that could be used all over Europe. And this Europe sub-proposal, in turn, included further sub-proposals for things like using "green bond" crowdfunding to finance solar energy projects.

\section{Alternative approaches to integrated contests}

\section{Defining integrated contests in different ways}

In the contests we have had so far, we defined integrated contests using the Where dimension (i.e., regional and global) because this dimension figures very prominently in many discussions of climate change.

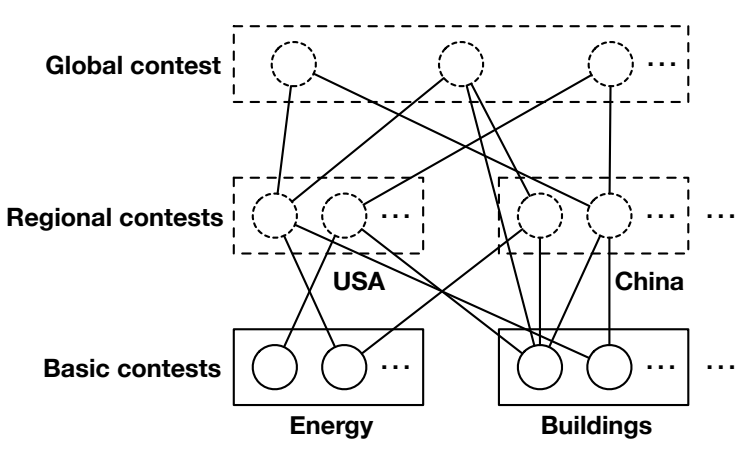

Figure 5. Elements of the Climate CoLab contest web. Boxes are contests. Circles are proposals. Dotted borders indicate integrated contests and integrated proposals. Solid borders indicate basic contests and basic proposals. Lines indicate that the proposal at the top of the line includes the one at the bottom. The entire figure is a contest family. Since this contest family includes integrated contests, it is also a contest web. (See Appendix 1 for glossary of terms.)

It would certainly be possible, however, to integrate along other dimensions. For instance, it might well be desirable to have integrated contests for what governments, businesses, and other organizations could do.

\section{Automated tools to help create integrated proposals}

The current version of Climate CoLab relies primarily on human authors and judges to evaluate the mutual compatibility and collective sufficiency of the combinations of sub-proposals included in integrated proposals. However, we believe there are substantial opportunities to create automated tools to help in this process. For example:

(a) Identifying candidates for subcomponents. To create a good integrated proposal, proposal authors may need to review many other proposals to find the best combination to include [36]. The Climate CoLab environment already provides some support for this process, such as simple keyword search, the Outline Viewer (Figure 4), and browse-by-contest. We also believe there are many opportunities for future extensions of these tools [44], and as an example are developing a tool to show topically related proposals.

(b) Constraint management. Another key challenge for proposal authors is making sure that the entries they combine are mutually compatible. In our work so far, we have relied completely on the proposal authors to assess this (and on the contest judges to determine how well the authors did). But we believe that, in many situations, it will be possible to have automated tools to help with this. For instance, checking whether a budget constraint is satisfied could, in some situations, be as simple as adding up the costs of different sub-proposals.

(c) Impact evaluation. Climate CoLab already uses built-in simulation models [20,21] to help proposal authors evaluate the overall impact of their proposals on emission reductions. But using these models appropriately requires a substantial amount of judgment. 
In some domains, it would be possible to have more detailed simulation models that could automatically calculate the impacts of various combinations of subproposals.

\section{MOTIVATING ACTIVITY: A VIRTUAL PRICE SYSTEM}

\section{Incentive systems for integrated contests}

For people to participate in any activity, including online contests, they need to be motivated to do so [19]. The analogy with supply webs for physical products suggests an obvious possibility for one way of doing this: The creators of integrated entries can "pay" the creators of the other entries they use. This payment could be in an actual currency (like dollars), or it could take some other form such as points that people can accumulate and then receive recognition for accumulating large numbers of points.

A key question for any such system is how to set the "prices" that integrated proposal creators pay. Whatever system is used should have at least the following desirable properties:

a) Motivates people to spend more time working on the parts of the problem that are most important to solving the overall problem

b) Does not provide strong incentives for gaming the system

c) Is relatively simple to understand and administer

d) Seems "fair" to participants

e) Does not "waste" effort.

In markets for physical products, the most common way of setting prices is to let buyers and sellers negotiate with each other in competitive markets. This method often satisfies the desirable criteria above reasonably well [5].

But in many situations, including Climate CoLab, the resources being exchanged are not physical products; they are information products. And information products, unlike physical ones, can often be used many times at virtually no additional cost.

In such situations, we know from information economics that an optimal allocation of resources often results from compulsory licensing, that is, requiring the creators of information to make it available to anyone who wants to use it $[4,19,37,39]$. Without this, some products that could easily be reused won't be and will thus be wasted.

However, to motivate people to create information products in the first place, they need to be compensated for their efforts, so a compulsory licensing method also needs a way of requiring the user to pay the creator a "fair" price. Various methods for determining such prices have been proposed, including the rights of national governments in developing countries to use legislative or judicial means to enforce compulsory licensing on pharmaceuticals (e.g. [37]).

\section{The Climate CoLab Points System}

Bearing these considerations in mind, we designed an incentive system for the Climate CoLab integrated contests that is based on "CoLab Points." CoLab Points are roughly analogous to the money that is transferred among different participants in a physical supply web.

Rather than requiring CoLab participants to negotiate with each other to determine how much an integrated proposal author needs to "pay" to incorporate a sub-proposal, we chose to use a form of compulsory licensing. This has the advantage of avoiding a potentially huge amount of negotiation among CoLab authors, some of whom might not even be available or willing to negotiate reasonably. This means that integrated proposal authors can use any combination of other proposals they want to without having to get permission from the authors of the other proposals.

To set prices for this compulsory licensing system, we begin with the judges in the global contest who, we assume, represent the "end customers" of the whole problemsolving system. The judges essentially "buy" the proposals they think are best, and they "pay" for each proposal the price they think it is worth. The points each global proposal receives are then distributed automatically to the authors of the global proposal and all the lower level proposals it contains. The details of the method we used to do this in the 2015 Climate CoLab contests are described in Appendix 2 , but the basic ideas are as follows:

(1) Using the supply web analogy, an integrated proposal team received "income" from selling their final proposal, and they had "expenses" for buying the other proposals they used. The difference between these two amounts is, loosely speaking, their "profit." For each level of integrated proposals, the contest rules specified the expenses and the allocation of those expenses to other proposals. We based these rules on our subjective assessments of the amount of work required for each type of proposal and its importance for the overall problem.

(2) At each level, the authors of a given proposal divided their profits among themselves in any way they agreed upon. This is similar to how founders of a company agree among themselves how to allocate equity shares in the company, and this seems like a fair way to do this allocation.

Together these incentives mean that:

a) Integrated proposal authors are motived to help authors in other contests create good, mutually compatible proposals and to create such proposals themselves if no one else will.

b) Basic proposal authors are motivated to create proposals that lots of higher-level proposal authors will want to use and to publicize their proposals to integrated proposal authors who can use them. 
In other words, even though proposal authors in a single contest compete with each other, the CoLab Points system provides incentives for them to collaborate with authors in higher- and lower-level contests.

\section{Alternative ways of allocating points}

It is certainly possible that the subjectively determined method we used for allocating points could be improved, and we believe this is an important direction of future work. A recent economic result, however, gives some basis for believing that determining a satisfactory allocation method may be easier than one might assume. This result suggests that socially efficient outcomes can be achieved, even without optimal allocations, as long as the participants believe that the allocations are "fair enough" to motivate their efforts [11].

\section{EVALUATION AND OBSERVATIONS}

\section{Contest families}

While it was not a primary hypothesis to be evaluated, we find it interesting that the creation of multiple contests in contest families may have been related to the number and quality of proposals we received. While we don't yet have enough data to definitively analyze the causal relationships statistically, our informal observation is that as we increased the number of contests in Climate CoLab over the years, the number, quality, and range of proposals submitted increased substantially. For instance, Figure 6 shows the close correspondence between the number of contests we had in each year and the number of proposals submitted in that year.

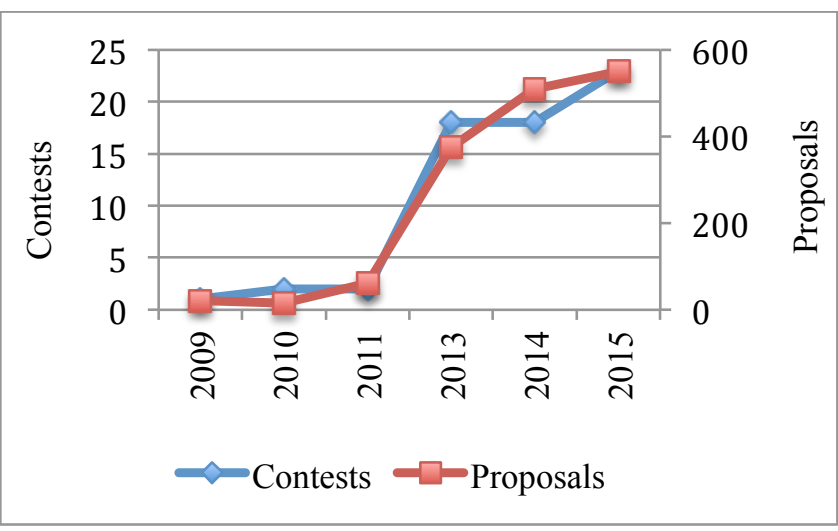

Figure 6. Number of contests and proposals by year

\section{Integrated contests}

As noted in the introduction, the two key questions we attempted to answer in this pilot study are: Would people simultaneously explore multiple combinations of interchangeable parts? And would they actually reuse their own and others' work? In this section, we first provide informal answers to these questions through visual inspection of the structural relationships among proposals. Then we analyze these relationships more formally using statistical tests.
Visual inspection of structural relationships

Figure 7 shows the relationships among the integrated proposals actually created in the 2015 Climate CoLab contests. Several aspects of this diagram are worth noting. First, it is clear from inspection of Figure 7 that proposal authors did explore multiple combinations of interchangeable parts. The global proposals (top row) include different combinations of regional proposals (middle rows), which in turn, include different combinations of basic proposals (bottom rows). In addition, as we anticipated, some global proposals also include direct links to basic proposals. And the interchangeability of these proposals is indicated by the fact that many lower level proposals are reused multiple times in different higher-level proposals.

It is also clear that proposal authors reuse work from themselves and others. For instance, the team represented by medium blue circles created the global proposal shown at the far left of the top row. This global proposal included regional proposals created by others and a basic proposal they created themselves. The regional proposals in this global proposal, in turn, included multiple basic proposals created by different author teams.

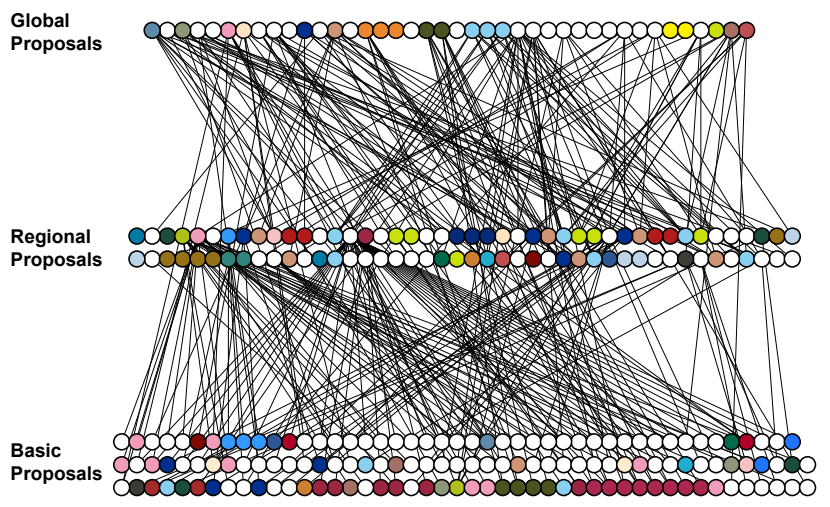

Figure 7. Relationships among proposals in the 2015 contests. Each circle represents a proposal. Lines indicate that the proposal above includes the one below. Different colors represent different author teams. White circles represent author teams with no other proposals in the diagram.

Do authors simultaneously explore multiple combinations of interchangeable parts?

To analyze more formally whether authors simultaneously explore multiple combinations of interchangeable parts, we use statistical tests to answer two questions.

First, we ask: Do authors reuse individual subparts in multiple places? In a system with non-interchangeable parts, each sub-proposal would be used in at most one higher-level proposal. But as Table 1 shows, $40 \%$ of the proposals that are used in any integrated proposal are used in more than one. Using Fisher's exact test to compare our empirical distribution to a null hypothesis where all 191 sub-proposals are each used in exactly one higher-level 
proposal, we reject the null hypothesis $(\mathrm{p}<<0.001)$. Thus our empirical results are consistent with the hypothesis that the subparts are reused in multiple places.

\begin{tabular}{c|cccc}
$\begin{array}{c}\text { No. of } \\
\text { uses }\end{array}$ & $\begin{array}{c}\text { Basic } \\
\text { proposals }\end{array}$ & $\begin{array}{c}\text { Regional } \\
\text { proposals }\end{array}$ & Total & $\%$ \\
\hline 1 & 91 & 23 & 114 & $60 \%$ \\
2 & 24 & 19 & 43 & $22 \%$ \\
3 & 1 & 9 & 10 & $5 \%$ \\
$\geq 4$ & 14 & 10 & 24 & $13 \%$ \\
Total & 130 & 61 & 191 & $100 \%$
\end{tabular}

Table 1. Number of times basic and regional proposals are used in higher-level integrated proposals.

Second, we ask: Do authors reuse individual subparts in multiple combinations? In a system where multiple combinations of subparts were not being explored, each subpart would always be used with the same other subparts. But as Table 2 shows, when a pair of proposals is used together in one higher-level proposal, the probability that if one of them is reused elsewhere, the other will be, too, is only $38 \%$. Using Fisher's exact test to compare this to a null hypothesis that they are always reused together, we reject the null hypothesis $(\mathrm{p}<<0.001)$. Thus our empirical results are consistent with the hypothesis that many different combinations are being explored.

\begin{tabular}{c|cccc}
$\begin{array}{c}\text { No. of times } \\
\text { reused }\end{array}$ & $\begin{array}{c}\text { Regional } \\
\text { proposals }\end{array}$ & $\begin{array}{c}\text { Global } \\
\text { proposals }\end{array}$ & Total & $\%$ \\
\hline $\begin{array}{c}\text { With other } \\
\text { proposal }\end{array}$ & 306 & 37 & 343 & $38 \%$ \\
$\begin{array}{c}\text { Without other } \\
\text { proposal } \\
\text { Total }\end{array}$ & 91 & 467 & 558 & $62 \%$ \\
\hline
\end{tabular}

Table 2. Number of times a member of a pair of proposals that is used together once is reused with or without the other in regional and global proposals.

Do authors reuse both their own and others' work?

If the authors of integrated proposals only wanted to use their own work (for instance, because they didn't trust the quality of anyone else's work), then all integrated proposals would include only sub-proposals by author teams with membership that overlapped the team creating the integrated proposal. Conversely, if authors didn't realize that they could use sub-proposals they created themselves, then all integrated proposals would include only work by others. However, as Table 3 shows, of the 348 uses of proposals at higher levels, $28 \%$ were uses of their own work, and $72 \%$ were uses of work by non-overlapping author teams. Using Fisher's exact test to compare this empirical data to null hypotheses assuming that authors never use their own work or always use their own work, we reject both null hypotheses ( $\mathrm{p}<<0.001$ in both cases). Thus our empirical results are consistent with the hypothesis that integrated proposal authors reuse both their own and others' work.

\begin{tabular}{c|cccc} 
No. of uses & $\begin{array}{c}\text { Basic } \\
\text { proposals }\end{array}$ & $\begin{array}{c}\text { Regional } \\
\text { proposals }\end{array}$ & Total & $\%$ \\
\hline Own work & 54 & 42 & 96 & $28 \%$ \\
Others' work & 159 & 93 & 252 & $72 \%$ \\
Total & 213 & 135 & 348 & $100 \%$
\end{tabular}

Table 3. Number of times integrated proposal author teams use basic or regional sub-proposals that are their own work (author teams with overlapping members) or others' work (author teams with no overlapping members).

\section{CoLab Points System}

We do not separately evaluate the effectiveness of the CoLab Points system, but we find it interesting to observe the distribution of CoLab Points that resulted from the point system (Figure 8). A total of 226 community members received CoLab Points, and the figure shows the distribution of these points among the 89 members who received 7 or more points. (The remaining 137 users would, if shown, appear as a very long tail to the right of the graph.) It is intriguing that this curve resembles scalefree distributions, which appear frequently in systems where "the rich get richer" such as income distributions, city sizes, and word frequencies [1,16]. Statistical tests [3] show that a power law fits our data significantly better than an exponential distribution $(\mathrm{p}<<0.001)$ and not significantly differently from a lognormal distribution $(\mathrm{p}>0.05$.)

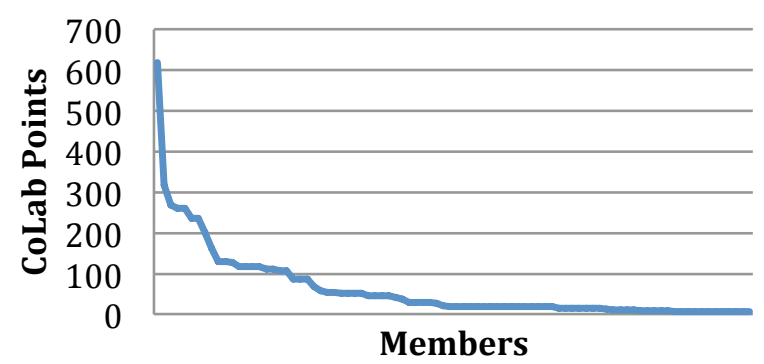

Figure 8. Distribution of CoLab Points among proposal authors in the 2015 Climate CoLab contests.

\section{Overall quality of proposals}

During the judging process, expert judges rated proposals on several dimensions (Appendix 3), and these ratings provide a rough way of gauging the quality of the proposals. As Table 4 shows, the averages of these ratings for the finalist integrated proposals are not significantly different from basic proposals (except for the presentation dimension where they are somewhat worse). This result is reassuring because it shows that our first major test of integrated proposals led to proposals that were judged roughly equivalent in quality to basic proposals like those we have been generating for eight years. 
But it is important not to over-interpret this comparison because these two kinds of proposals are not directly comparable to each other, any more than complete cars are directly comparable to car batteries. Complete cars can do many things their batteries alone cannot, and people judging their quality presumably take into account different factors in the two cases. In the same way, integrated proposals have greater scope and are presumably judged by different standards than the basic proposals they contain.

As a rough indication of the overall quality of both kinds of proposals, we can round the judges' average ratings to the nearest whole number. For all the dimensions rated, this results in 3's on a scale from 1 to 4 . According to the scales used, therefore, these ratings indicated proposals that were interesting and imaginative, with acceptable feasibility, moderate impact, and two of the following three presentation characteristics: clear, persuasive, and appealing. Even though this is not a rigorous evaluation relative to a clear external standard, it is at least a rough indication that the proposals are solid and worthwhile but could still be improved.

\begin{tabular}{l|cc} 
& $\begin{array}{c}\text { Basic } \\
\text { Proposals }\end{array}$ & $\begin{array}{c}\text { Integrated } \\
\text { Proposals }\end{array}$ \\
\hline Novelty & 2.7 & 2.8 \\
Feasibility & 3.0 & 2.6 \\
Impact & 3.0 & 2.7 \\
Presentation & 3.1 & $2.6^{*}$ \\
Average & 2.9 & 2.7 \\
(No. of observations) & 63 & 8
\end{tabular}

Table 4. Quality of finalist proposals in basic and integrated contests as rated by judges. $(* p<.05)$

\section{DISCUSSION}

When we first described the idea of combining ideas in integrated contests, many people were very skeptical that it could work. They asked questions like: Could a large, diverse crowd even understand the basic concepts of the approach well enough to create integrated proposals with the multi-layered structure we intended? Would people be able to simultaneously explore multiple ways of doing this? Would the creators of integrated proposals be able to find enough other proposals to include in theirs? And would people be motivated enough to spend time combining other people's ideas instead of just developing their own?

We believe one of the most important results of the pilot testing described here is to answer all these questions in the affirmative. We showed that it was possible for a diverse crowd of people from all over the world to simultaneously create multiple, sensible integrated proposals using a combination of their own and other's work.

What is needed to use a contest web in a new domain? To create a contest web in a new domain, one needs to do the following:
(1) Identify an overall problem complex enough for different people to work on different parts.

(2) Create one or more basic contests, each for a different part of the overall problem.

(3) Create one or more integrated contests that combine entries from other contests. Generally, one of these integrated contests will be for solutions to the overall problem, and there may be others for solutions to various levels of subparts.

(4) Identify incentives that will be sufficient to motivate people to participate effectively. One promising component of such incentives is a point system (like CoLab Points).

The open source software platform we developed to support these things for Climate CoLab is called XCoLab and is designed to be easily customizable for other problem domains. The main changes needed to use the system in a new problem area are adding new content (e.g., a new set of basic and integrated contests). In some cases, it may also be appropriate to add new modeling or constraint management tools.

Using this approach, we have recently launched several new sites for other problem domains. For instance, working with the MIT Solve initiative, we have developed a site for tackling other societal problems such as education, and healthcare (http://solvecolab.mit.edu). And we believe a similar approach can be used to address problems inside individual organizations such as strategic planning and product design.

\section{When are contest webs desirable?}

There are a number of situations where the contest web approach may be particularly useful relative to previous CSCW approaches. For instance, as noted above [6,46,51], simultaneously exploring multiple combinations of reusable parts can substantially increase the likelihood of innovation and rapid adaptation relative to purely top-down approaches $[25,38]$. In contrast, most previous CSCW examples, including both top-down hierarchies and communities like Wikipedia, explore only one solution alternative at a time.

By exploring many alternatives in parallel, while still reusing previous work as much as possible, the contest web approach may be especially useful for problems that are very important (where extensive effort is justified), very urgent (where parallel efforts may be critical), and/or very controversial (where working in a single group may be difficult). Finally, the contest web approach can be used even in situations where domain-specific automated tools (e.g., $[8,9,22,50])$ are not available.

\section{Competition and cooperation}

Another intriguing aspect of contest webs is how they integrate cooperation and competition in the same environment. For instance, the Popular Choice global winner in the 2015 global contest began with a US regional 
proposal by a user whose user profile described her as a "biocentric stay-at-home mom." After posting her original proposal, authors of several other proposals contacted her, and they agreed to cooperate on a global proposal that eventually included over 25 authors. Even though many members of this team did not know each other before "meeting" on the Climate CoLab site and some had competing proposals, many of them are now actively working together to raise money for the ideas in their proposals.

\section{Limitations}

The current study demonstrates that teams were able to create proposals of reasonable quality with the desirable structural characteristics we intended, but we believe more systematic measurement of proposal quality is highly desirable. We also believe that substantial improvements in quality are possible. To increase the quality of the best proposals in future contests, we hope to explore possibilities such as: more explanatory material on the site about creating integrated proposals, more recruiting of people likely to create good proposals, stronger incentives, and tools that make it easier for people to find and integrate other proposals.

\section{CONCLUSIONS}

This paper describes a way of using online contest webs to divide and combine different parts of a complex problem. Drawing on an analogy with how multiple suppliers create complex physical products, this method shows how members of an online community can create complex knowledge artifacts that represent the solutions to complex problems. The method (a) combines solutions to sub-parts of the problem at multiple levels of aggregation, (b) encourages widespread knowledge sharing and reuse, and (c) provides incentives for knowledge creation based on how useful the knowledge is to others.

We believe the results of our early testing of this method demonstrate that the method can work effectively in a large-scale community that is addressing a complex problem, and we believe the approach can be applied much more widely for many other kinds of problems.

In the long run, we hope this new approach will provide one more powerful tool in the world's design toolkit for solving important societal and organizational problems.

\section{ACKNOWLEDGMENTS}

We are grateful for financial support of this work from the following sponsors: US National Science Foundation (grant numbers IIS-0968321, IIS-1144663, IIS-1302522, IIS-1211084, IIS-1422066, CCF-1442887, and CCF1442840), Swiss National Science Foundation (Project 200021 - 143411), US Army Research Office (grant number W911NF-15-1-0577), V. Kann Rasmussen Foundation, Argosy Foundation, MIT Sloan School of Management, MIT Sustainability Initiative, MIT Energy Initiative, and other sponsors of the MIT Center for Collective
Intelligence. We are also very grateful to Gary Olson for his participation in this project and his advice on this paper. Finally, we thank the many people who volunteered their time for organizing, judging, and participating in the contests described here, making this project possible. The images in Figures 1, 2, and 4 are from the Climate CoLab website and are subject to the following license:

https://creativecommons.org/licenses/by-nc-sa/3.0/us/.

\section{REFERENCES}

1. Lada A. Adamic. 2002. Zipf, Power-laws, and Pareto a ranking tutorial. Retrieved August 5, 2016 from http://www.hpl.hp.com/research/idl/papers/ranking/ran king.html

2. Robert J. Allio. 2004. CEO Interview: The InnoCentive Model of Open Innovation. Strategy \& Leadership 32, 4: 4-9. https://doi.org/10.1108/10878570410547643

3. Jeff Alstott, Ed Bullmore, and Dietmar Plenz. 2014. powerlaw: A Python Package for Analysis of HeavyTailed Distributions. PLOS ONE 9, 1: e85777. https://doi.org/10.1371/journal.pone.0085777

4. Kenneth J. Arrow. 1962. Economic Welfare and the Allocation of Resources for Invention. In The Rate and Direction of Inventive Activity: Economic and Social Factors, Universities-National Bureau Committee for and Committee on Economic Growth of the Social Science Research Council (eds.). Princeton University Press, Rochester, NY, 609-626. Retrieved from www.nber.org/chapters/c2144.pdf

5. Kenneth J. Arrow and Gerard Debreu. 1954. Existence of an equilibrium for a competitive economy. Econometrica: Journal of the Econometric Society: 265-290.

6. Carliss Young Baldwin and Kim B. Clark. 2000. Design Rules: The Power of Modularity. MIT Press, Cambridge, MA.

7. Joel Chan, Steven P. Dow, and Christian D. Schunn. 2015. Do the best design ideas (really) come from conceptually distant sources of inspiration? Design Studies 36: 31-58. https://doi.org/10.1016/j.destud.2014.08.001

8. Lydia B. Chilton, Juho Kim, Paul André, Felicia Cordeiro, James A. Landay, Daniel S. Weld, Steven P. Dow, Robert C. Miller, and Haoqi Zhang. 2014. Frenzy: Collaborative Data Organization for Creating Conference Sessions. In Proceedings of the SIGCHI Conference on Human Factors in Computing Systems (CHI '14), 1255-1264. https://doi.org/10.1145/2556288.2557375

9. Lydia B. Chilton, Greg Little, Darren Edge, Daniel S. Weld, and James A. Landay. 2013. Cascade: Crowdsourcing Taxonomy Creation. In Proceedings of the SIGCHI Conference on Human Factors in Computing Systems (CHI '13), 1999-2008. https://doi.org/10.1145/2470654.2466265 
10. Ellen Christiaanse and Kuldeep Kumar. 2000. ICTenabled coordination of dynamic supply webs. International Journal of Physical Distribution \& Logistics Management 30, 3/4: 268-285.

11. Gavin Clarkson and Marshall Van Alstyne. 2007. The Social Efficiency of Fairness: An Innovation Economics Approach to Innovation. In 40th Annual Hawaii International Conference on System Sciences (HICSS '07), 155b-155b. https://doi.org/10.1109/HICSS.2007.554

12. Ronald H. Coase. 1937. The Nature Of The Firm. Economica 4, 16: 386-405.

13. Kenneth Davis. 2015. InnoCentive.com Collaboration Case Study. Journal of Management 3, 1: 20-22.

14. Jeffrey Dean and Sanjay Ghemawat. 2008. MapReduce: Simplified Data Processing on Large Clusters. Communications of the ACM 51, 1: 107-113. https://doi.org/10.1145/1327452.1327492

15. Erik P. Duhaime, Gary M. Olson, and Thomas W. Malone. 2015. Broad Participation in Collective Problem Solving Can Influence Participants and Lead to Better Solutions: Evidence from the MIT Climate CoLab. MIT Center for Collective Intelligence, Cambridge, MA. Retrieved from http://cci.mit.edu/working_papers_2012_2013/duhaim e\%20colab\%20wp\%206-2015\%20final.pdf

16. David Easley and Jon Kleinberg. 2010. Power Laws and Rich-Get-Richer Phenomena. In Networks, Crowds, and Markets: Reasoning About a Highly Connected World. Cambridge University Press, 543560. Retrieved from https:/www.cs.cornell.edu/home/kleinber/networksbook/networks-book-ch18.pdf

17. Jay R. Galbraith. 1995. Designing organizations: An executive briefing on strategy, structure, and process. Jossey-Bass.

18. David Hounshell. 1985. From the American System to Mass Production, 1800-1932: The Development of Manufacturing Technology in the United States. JHU Press.

19. James Howison and James D. Herbsleb. 2013. Incentives and Integration in Scientific Software Production. In Proceedings of the ACM Conference on Computer Supported Cooperative Work (CSCW'13), 459-470. https://doi.org/10.1145/2441776.2441828

20. Joshua Introne, Robert Laubacher, and Thomas Malone. 2011. Enabling Open Development Methodologies in Climate Change Assessment Modeling. IEEE Software 28, 6: 56-61. https://doi.org/10.1109/MS.2011.115

21. Joshua Introne, Robert Laubacher, Gary Olson, and Thomas Malone. 2011. The Climate CoLab: Large Scale Model-based Collaborative Planning. In International Conference on Collaboration Technologies and Systems (CTS), 40-47. https://doi.org/10.1109/CTS.2011.5928663
22. Juho Kim, Haoqi Zhang, Paul André, Lydia B. Chilton, Wendy Mackay, Michel Beaudouin-Lafon, Robert C. Miller, and Steven P. Dow. 2013. Cobi: A Community-informed Conference Scheduling Tool. In Proceedings of the 26th Annual ACM Symposium on User Interface Software and Technology (UIST '13), 173-182. https://doi.org/10.1145/2501988.2502034

23. Aniket Kittur, Jeffrey V. Nickerson, Michael Bernstein, Elizabeth Gerber, Aaron Shaw, John Zimmerman, Matt Lease, and John Horton. 2013. The Future of Crowd Work. In Proceedings of the ACM Conference on Computer Supported Cooperative Work (CSCW'13), 1301-1318. https://doi.org/10.1145/2441776.2441923

24. Aniket Kittur, Boris Smus, Susheel Khamkar, and Robert E. Kraut. 2011. CrowdForge: Crowdsourcing Complex Work. In Proceedings of the 24th Annual ACM Symposium on User Interface Software and Technology (UIST '11), 43-52.

https://doi.org/10.1145/2047196.2047202

25. Anand Kulkarni, Matthew Can, and Björn Hartmann. 2012. Collaboratively Crowdsourcing Workflows with Turkomatic. In Proceedings of the ACM Conference on Computer Supported Cooperative Work (CSCW '12), 1003-1012. https://doi.org/10.1145/2145204.2145354

26. Karim Lakhani, David A. Garvin, and Eric Lonstein. 2010. TopCoder (A): Developing Software Through Crowdsourcing. Harvard Business School General Management Unit Case, 610-32.

27. Karim R. Lakhani, Anne-Laure Fayard, Natalia Levina, and Stephanie Healy Pokrywa. 2012. OpenIDEO. Harvard Business School Technology \& Operations Management Unit Case, 612-66.

28. Thomas D. LaToza, W. Ben Towne, Christian M. Adriano, and André van der Hoek. 2014. Microtask Programming: Building Software with a Crowd. In Proceedings of the 27th Annual ACM Symposium on User Interface Software and Technology (UIST '14), 43-54. https://doi.org/10.1145/2642918.2647349

29. Paul R. Lawrence and Jay W. Lorsch. 1967. Differentiation and Integration in Complex Organizations. Administrative Science Quarterly 12, 1: $1-47$.

30. Charlotte P. Lee and Drew Paine. 2015. From The Matrix to a Model of Coordinated Action (MoCA): A Conceptual Framework of and for CSCW. In Proceedings of the ACM Conference on Computer Supported Cooperative Work \& Social Computing (CSCW'15), 179-194. https://doi.org/10.1145/2675133.2675161

31. Thomas W. Malone and Kevin Crowston. 1994. The Interdisciplinary Study of Coordination. $A C M$ Computing Surveys (CSUR) 26, 1: 87-119. https://doi.org/10.1145/174666.174668 
32. Thomas W. Malone and Mark Klein. 2007. Harnessing Collective Intelligence to Address Global Climate Change. Innovations 2, 3: 15-26.

33. Thomas W. Malone, Robert Laubacher, and Laur Fisher. 2014. How Millions of People Can Help Solve Climate Change. PBS NOVA Next. Retrieved January 18,2014 from http://www.pbs.org/wgbh/nova/next/earth/crowdsourci ng-climate-change-solutions/

34. David A. Nadler and Michael L. Tushman. 1997. Competing by Design: The Power of Organizational Architecture. Oxford University Press, New York.

35. Jeffrey V. Nickerson and Andres Monroy-Hernandez. 2011. Appropriation and Creativity: User-Initiated Contests in Scratch. In 44th Hawaii International Conference on System Sciences (HICSS '11), 1-10. https://doi.org/10.1109/HICSS.2011.75

36. Pinar Ozturk, Yue Han, W. Ben Towne, and Jeffrey V. Nickerson. 2016. Topic Prevalence and Reuse in an Open Innovation Community. In Collective Intelligence. Retrieved from https://sites.google.com/a/stern.nyu.edu/collectiveintelligence-conference/

37. Jerome H. Reichman. 2009. Intellectual Property in the Twenty-First Century: Will the Developing Countries Lead or Follow? Houston Law Review 46, 4: 11151185 .

38. Daniela Retelny, Sébastien Robaszkiewicz, Alexandra To, Walter S. Lasecki, Jay Patel, Negar Rahmati, Tulsee Doshi, Melissa Valentine, and Michael S. Bernstein. 2014. Expert Crowdsourcing with Flash Teams. In Proceedings of the 27th Annual ACM Symposium on User Interface Software and Technology (UIST'14), 75-85. https://doi.org/10.1145/2642918.2647409

39. Lloyd S. Shapley. 1953. Stochastic Games. Proceedings of the National Academy of Sciences 39, 10: 1095-1100. https://doi.org/10.1073/pnas.39.10.1095

40. Herbert Alexander Simon. 1996. The Sciences of the Artificial. MIT Press.

41. Adam Smith. 1776. An Inquiry Into the Nature and Causes of the Wealth of Nations. Strahan \& Cadell, The Strand, London. Retrieved from https://books.google.com/books?id=C5dNAAAAcAAJ

42. Thomas F. Stocker, Dahe Qin, Gian-Kasper Plattner, Melinda M.B. Tignor, Simon K. Allen, Judith Boschung, Alexander Nauels, Yu Xia, Vincent Bex, and Pauline M. Midgley (eds.). 2013. Climate Change 2013- The Physical Science Basis: Working Group I Contribution to the Fifth Assessment Report of the Intergovernmental Panel on Climate Change. Cambridge University Press, Cambridge, UK. Retrieved from https://www.ipcc.ch/pdf/assessmentreport/ar5/wg1/WG1AR5_SummaryVolume_FINAL.p df
43. James D. Thompson. 1967. Organizations in Action: Social Science Bases of Administrative Theory. Transaction Publishers.

44. W. Ben Towne, Carolyn P. Rosé, and James D. Herbsleb. 2016. The Key Role of Navigation in Online Challenge Platforms. Retrieved from https://sites.google.com/a/stern.nyu.edu/collectiveintelligence-conference/

45. U.S. Energy Information Administration. 2013. International Energy Outlook 2013. Energy Information Administration, Washington, DC. Retrieved July 25, 2013 from https://www.eia.gov/forecasts/archive/ieo13/

46. David Weinberger. 2003. Small Pieces Loosely Joined: A Unified Theory of The Web. Basic Books.

47. Oliver E. Williamson. 1975. Markets and Hierarchies, Analysis and Antitrust Implications: A Study in the Economics of Internal Organization. Free Press. Retrieved from https://books.google.com/books?id=IFm3AAAAIAAJ

48. Lixiu Yu, Aniket Kittur, and Robert E. Kraut. 2014. Distributed Analogical Idea Generation: Inventing with Crowds. In Proceedings of the SIGCHI Conference on Human Factors in Computing Systems (CHI '14), 1245-1254. https://doi.org/10.1145/2556288.2557371

49. Lixiu Yu, Aniket Kittur, and Robert E. Kraut. 2014. Searching for Analogical Ideas with Crowds. In Proceedings of the SIGCHI Conference on Human Factors in Computing Systems (CHI '14), 1225-1234. https://doi.org/10.1145/2556288.2557378

50. Haoqi Zhang, Edith Law, Rob Miller, Krzysztof Gajos, David Parkes, and Eric Horvitz. 2012. Human Computation Tasks with Global Constraints. In Proceedings of the SIGCHI Conference on Human Factors in Computing Systems (CHI '12), 217-226. https://doi.org/10.1145/2207676.2207708

51. Jonathan Zittrain. 2008. The Future of the Internet-And How to Stop It. Yale University Press.

\section{APPENDIX 1: GLOSSARY}

Proposal - an entry submitted in a contest (e.g., Climate CoLab proposals contain proposed solutions to various aspects of the problem of what to do about climate change).

Contest - a collection of proposals on the same topic from which judges select finalists and winners.

Contest family - a collection of related contests that, together, systematically cover different aspects of a complex problem.

Integrated proposal - a proposal that explicitly combines (by reference) proposals from other contests in the same contest family.

Integrated contest - a contest in which the entries are integrated proposals.

Contest web - a contest family that includes one or more integrated contests. 


\section{APPENDIX 2: POINT ALLOCATION METHOD}

In the 2015 Climate CoLab global contest, the judges had a total of 10,000 CoLab Points to allocate, and they divided these points as shown in Table 5. These points were then divided among all the people who contributed to the global proposals as summarized in Table 6 .

\begin{tabular}{l|c|c|c|c|c} 
Place & $1^{\text {st }}$ & $2^{\text {nd }}$ & $3^{\text {rd }}($ tie $)$ & $5^{\text {th }}$ & Total \\
\hline Points & 6,000 & 1,833 & $1,000($ each $)$ & 167 & 10,000
\end{tabular}

Table 5. Judges' allocation of points among winning global proposals.

How were points divided among the authors of integrated proposals and the proposals they contained?

For the 2015 contests, we determined the point allocation for integrated proposal authors based on our subjective assessments of the amount of work required for the different levels of proposals. Since regional proposal authors may have needed to review and incorporate dozens of basic proposals from many different areas, while global proposal authors only needed to review and select from among proposals in the six regional categories, we estimated that the regional authors had to do roughly twice as much work as the global authors.

In both cases, we also estimated that most of the important work was being done by the many authors who created the sub-proposals that were included in these integrated proposals. These assessments led us to the allocations of $5 \%$ and $10 \%$, respectively, as the "profits" received by the global and regional author teams.

The authors of basic proposals, of course, received as profit all the points their proposals received, since they had no other expenses.

How were points allocated among the different proposals included in an integrated proposal?

At the global level, we assumed that it was most important to have good regional plans for the regions that would otherwise account for the most emissions. To estimate this, we used projections of the "business as usual" scenarios for the different regions in 2050 (the end of the planning period we considered) [45].
At the regional level, we assumed that, if we asked the regional proposal authors to estimate how important the different proposals they used were, there would be strong temptations to game the system. So, instead, we used the straightforward approach of simply dividing a regional proposal's expenses equally among all the proposals it used. While this is certainly an approximation, we felt that this simple method was a reasonable approach with which to start.

\section{APPENDIX 3: PROPOSAL RATING SCALE}

Novelty: The degree to which the proposal is original (not only rare but also ingenious, imaginative, or surprising), and modifies a paradigm.

$1=$ Common, mundane, boring

$2=$ Interesting, but not unheard of

3 = Unusual, interesting; imaginative

4 = Rare; surprising; challenges paradigms

Feasibility: The degree to which the proposal is appealing (socially, legally and politically) and implementable (technically and economically)

1 = Infeasible socially, politically, legally, or technically

2 = Challenging; feasibility is questionable

3 = Acceptable; Objections \& barriers partially addressed 4 = Appealing; Potential objections \& barriers well addressed

Impact: The degree to which the proposal, if successfully implemented, will be effective at solving the challenge in the contest prompt

$1=$ Benefits/impact not clear

$2=$ Limited benefits/small impact

$3=$ Partial solution/moderate impact

4 = Large, direct, \& positive impact

Presentation: The degree to which the proposal is presented in a clear, persuasive and appealing manner

$1=$ Neither clear, persuasive, nor appealing

$2=1$ of 3: Clear, Persuasive, Appealing

$3=2$ of 3: Clear, Persuasive, Appealing

$4=3$ of 3: Clear, Persuasive, Appealing

\begin{tabular}{c|c|c|c|c} 
Level & $\begin{array}{c}\text { \% of points } \\
\text { to proposal } \\
\text { creators }\end{array}$ & $\begin{array}{c}\text { How are points } \\
\text { allocated among } \\
\text { proposal creators? }\end{array}$ & $\begin{array}{c}\text { \%o of points } \\
\text { to included } \\
\text { proposals }\end{array}$ & $\begin{array}{r}\text { How are points allocated among } \\
\text { included proposals? }\end{array}$ \\
\hline Global & $5 \%$ & Mutual agreement & $95 \%$ & $\begin{array}{l}\text { Proportional to projected emissions for each region } \\
\text { under "business as usual” in 2050 }\end{array}$ \\
Regional & $10 \%$ & “ & $90 \%$ & Divided equally among all proposals included \\
Basic & $100 \%$ & “ & $0 \%$ & Not applicable
\end{tabular}

Table 6. Method for allocating points from integrated proposals in the 2015 Climate CoLab contests 